\title{
PROXIMAL HUMERAL EPIPHYSIOLYSIS IN A GYMNAST
}

\author{
Benno Eunisman ${ }^{1}$, Carlos Vicente Andreol ${ }^{2}$, Alberto de Castro Pochin² ${ }^{2}$, Gustavo Cará Monteiro², \\ flávio Faloppa ${ }^{3}$, Molsés COHEN ${ }^{4}$, ABdalla Youssef SKaF
}

\section{SUMMARY}

Context: There are different causes for shoulder pain in athletes. Structures such as tendons and ligaments are frequently affected by injuries. In young athletes with immature skull, bone injuries must be ruled as a cause of pain. Case Report: The authors present a case of proximal humeral epiphysiolysis in a gymnast and review literature addressing this topic. Conclusion: Injuries on proximal humeral physeal plates of athletes are uncommon. The early diagnosis and correct treatment can avoid deformity and functional deficits.

Keywords: Epiphysiolysis; Proximal Humerus; Little League Shoulder

Citation: Ejnisman B, Andreoli CV, Pochini AC, Monteiro GC, Faloppa F, Cohen M et al. Proximal humeral epiphysiolysis in a gymnast. Acta Ortop Bras. [serial on the Internet]. 2007; 15(5): 290-291. Available from URL: http://www.scielo.br/aob.

\section{INTRODUCTION}

Proximal humeral epiphysiolysis is described in young pitcher athletes submitted to shoulder joint overload. The vast majority of the reports is from American literature and associated to baseball games. We describe its occurrence in a gymnast.

\section{CASE REPORT}

The subject is a 15 year-old boy who had practiced gymnastics for nine years, on an international competitive level. This athlete's expertise was the ring apparatus, in which he was a national champion.

He came to the medical office complaining of pain of insidious onset on the right shoulder for the three previous months, and no trauma history. He presented a progressively worse pain, which precluded him to practice sports.

Physical examination revealed no changes at inspection, palpation or range of motion. Special maneuvers revealed diffuse unspecific pain at proximal humeral region.

$X$-ray images evidenced enlargement of the right proximal humerus' physeal plate when compared to contralateral side, which was asymptomatic (Figures 1 and 2).

Tomography and magnetic resonance were indicated to probe potential associated injuries. These tests confirmed $X$-ray findings, and no further injuries were found. A bone scintiscan test was conducted, providing a diagnosis of increased captivation on physeal plates of proximal humera when compared to other growth plates.

The athlete was submitted to conservative therapy, refraining from practicing sports for a period of three months. Then, a rehabilitation program was established, targeting specific strengthening.

Follow-up studies revealed physeal plate closure after five months, with subtle angle deformity in varus (Figure 3). We measured the axial angle ${ }^{(1)}$. That measurement on X-ray images revealed a deformity in varus on the affected side, being found an axial angle of 39 degrees (Figure 4). The asymptomatic shoulder showed an axial angle of 59 degrees, which is within normal range (Figure 5). Measurements of the humeral head retroversion were made by tomography, and the values found were normal, being 49 degrees of retroversion on both humera (Figure 6).

As a criterion for resuming sports activities, the patient was submitted to an isokinetic assessment, which evidences good muscle balance. The patient remained asymptomatic during the following two months and no changes were noticed at physical examination.

\section{DISCUSSION}

A teenager athlete's skeleton shows features such as ligament laxity, developing muscles and the presence of open physeal growth plates, which can favor the occurrence of overload injuries.

On the shoulder, the involvement of the physeal plate of the proximal humerus was first described by Dotter ${ }^{(2)}$. This injury was found in young baseball players and was named as Little League Shoulder, in a reference to the U.S. Young Baseball League. Other authors have written about this injury, using different names such as proximal humeral epiphyseal osteochondrosis, proximal humeral epiphysiolysis, and stress fracture of the proximal humeral epiphyseal plate ${ }^{(3-7)}$.

The vast majority of reports address baseball players, but such injury has also been described in cricket players and gymnastic athletes ${ }^{(8,9)}$.

Clinical picture is characterized by shoulder pain of insidious onset progressively worsened during sports practice. Although some studies evidence the enlargement of the growth plate in some asymptomatic pitchers, all symptomatic athletes showed that radiographic change $\mathrm{e}^{(3,10,11)}$.

There are some biomechanical factors involved in the mechanism of injury of the physeal plate. This bone region experiences fatigue when submitted to repeated trauma at pitching movement. Rotator cuff tendons are inserted on

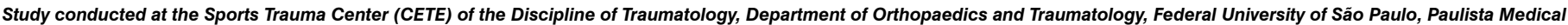
School (UNIFESP/EPM)

Correspondences to: Dr. Gustavo Cará Monteiro. Rua Pedro de Toledo, 394-Vila Clementino-São Paulo-SP. Cep: 04039-061 - E-mail: gucara@uol.com.br

1. Ph.D. in Orthopaedics, Assistant Doctor, Sports Trauma Center (CETE/Unifesp); Assistant Doctor, Shoulder and Elbow Group, Unifesp/EPM

2. Assistant Doctor, Sports Trauma Center (CETE/Unifesp)

3. Full Professor, Head of the Department of Orthopaedics and Traumatology, Unifesp/EPM

4. Full Professor, Head of the Sports Trauma Center (CETE/Unifesp)

5. Head of the Department of Magnetic Resonance, Laboratório Fleury - Medicina Diagnóstica 


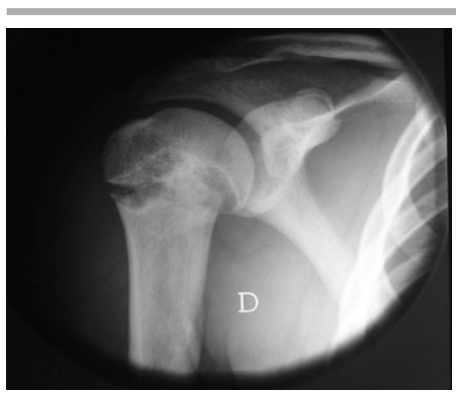

Figure 1 - X-ray image of the proximal region of right humerus evidencing physeal plate enlargement.
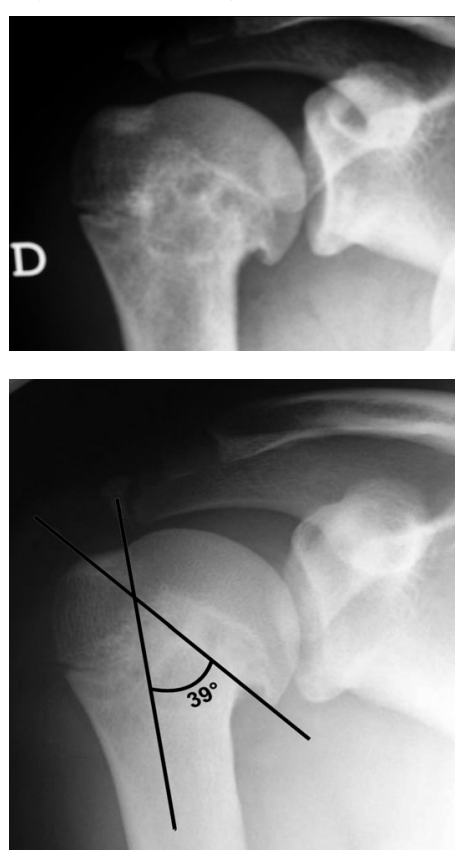

Figure 4 - X-ray image of the proximal region of right humerus with a 20-degree deformity in varus.

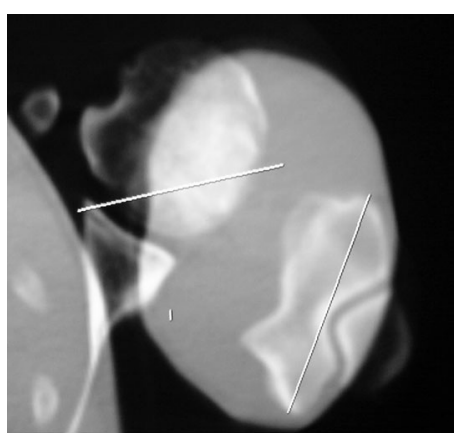

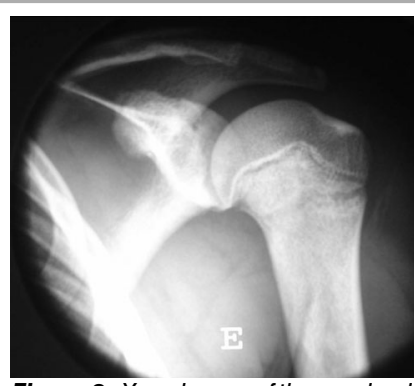

Figure 2-X-ray image of the proximal region of left humerus evidencing a normal physeal plate.

Figure 3-X-ray image of the proximal region of the humerus evidencing physeal plate closing and deformity in varus on the right humerus.

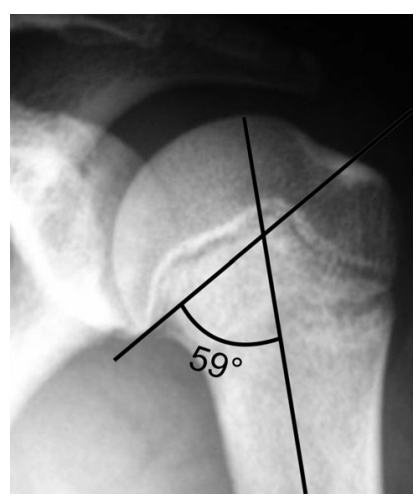

Figure 5 - X-ray image of the proximal region of left humerus with normal axial angle measurement.

Figure 6 - Measurement of humeral retroversion at computed tomography. the proximal humeral epiphysis and strong and repeated rotation movements generate rotational shearing forces on a physeal plate. Although biomechanical studies evidence that the physeal plate of proximal humerus is more susceptible to injury by rotational torques, distraction forces also occur at pitching and may be correlated to the mechanism of injury ${ }^{(10,12,13)}$

Treatment consists of reducing the activity until symptoms are improved $^{(7,14)}$. According to Carson, that recovery period lasts three months, in average. Sports practice should be gradually resumed(3).

This injury generates humeral torsional adjustments. Usually, those athletes show a greater retroversion of the proximal dominant humerus epiphysis compared to the non-dominant side $^{(12,15)}$

According to Edelson, an individual shows a marked retroversion at birth, of 65 degrees in average. This retroversion is reduced with skeleton development and reaches values around 27 to 33 degrees in adults ${ }^{(16)}$. Thus, a reduction on retroversion correction would occur during a teenager pitcher's development, and that individual would reach adult age with higher proximal humeral epiphysis retroversion values on the dominant limb when compared to the non-dominant limb. Most of this retroversion correction occurs before the age of eight, meaning that a younger pitcher is at higher risk of maintaining retroversion. However, physeal plate is closed between 18 and 21 years old, and, theoretically, injuries can occur until that age.

That bone adjustment, associated to capsuloligamentar adjustments, makes athletes to present a higher lateral rotation range on the shoulder associated to a reduced medial rotation. That increment of lateral rotation favors pitch movements, but it is not clear from literature whether that adjustment leads to a higher incidence of shoulder injuries when the athlete grows adult or not ${ }^{(10,17)}$.

A gymnast does not pitch any object, but the sportive gesture in some apparatus such as in rings requires movements with strong rotational torque. The athlete presented with a clinical picture and X-ray changes consistent to proximal humeral epiphysiolysis. X-ray and computed tomography studies did not evidence the rotational changes described for baseball pitchers. An angle change with varus shift was found on proximal humeral epiphysis. At evolution, the growth plate was united without functional deficit of the shoulder. The athlete was asymptomatic and back to competitions at the same previous sportive level.

The residual deformity in varus on proximal humerus had no clinical repercussion. The athlete was back to sport at the same performance level, and joined the national team.

\section{REFERENCES}

1. Lusted LB, Keats TE. Atlas of roentegenographic measurement. Year Book Medical Publishers, Chicago, EUA. 3a. edição, 1973

2. Dotter WE. Little league shoulder. Guthrie Clin Bull. 1953; 23:68-72.

3. Carson WG, Gasser SI. Litlle league's shoulder. A report of 23 cases. Am J Sports Med. 1998; 26:575-580.

4. Ireland ML, Andrews JR. Shoulder and elbow injuries in the young athlete. Clin Sports Med. 1988; 7:473-94.

5. Tibone JE. Shoulder problems of adolescents. Clin Sports Med. 1983; 2:423-7.

6. Ricci AR, Mason DE. Little league shoulder: case report and literature review. Del Med J. 2004; 76: 11-14

7. Barnett LS. Little league shoulder syndrome: proximal humeral epiphysiolysis in adolescent baseball pitchers. A case report. J Bone Joint Surg Am. 1985; 67:495-6.

8. Drescher WR, Falliner A, Zantop T, Oehlert K, Petersen W, Hassenpflug J. Litlle league shoulder syndrome in an adolescent cricket player. Br J Sports Med. 2004; 38: 1-2.

9. Dalldorf PG, Bryan WJ. Displaced Salter-Harris type I injury in a gymnast. A slipped capital humeral epiphysis? Orthop Rev. 1994; 23:538-41.

10. Mair SD, Uhl TL, Robbe RG, Brindle KA. Physeal changes and range-of-motion differences in the dominant shoulders of skeletally immature baseball players. J Shoulder

Elbow Surg. 2004; 13:487-91.

11. Fleming JL, Hollingsworth CL, Squire DL, Bisset GS. Little leaguer's shoulder. Skeletal Radiol. 2004. 33.352-4.

12. Sabick MB, Kim YK, Torry MR, Keirns MA, Hawkins RJ. Biomechanics of the shoulder in youth baseball pitchers. Implications for the development of proximal humeral epiphysiolysis and humeral retrotorsion. Am J Sports Med. 2005; 33: 1-7.

13. Osbahr DC, Cannon DL, Speer KP. Retroversion of the humerus in the throwing shoulder of the college baseball pitchers.. Am J Sports Med. 2002; 30:347-53.

14. Adams JE. Bone injuries in the very young athlete. Clin Orthop Relat Res. 1968; (58):129-40.

15. Meister K, Day T, Horodyski M, Kaminski TW, Wasik MP, Tillman S. Rotational motion changes in the glenohumeral joint of the adolescent / Little league baseball player. Am J Sports Med. 2005; 33:693-8.

16. Edelson G. The development of humeral head retroversion. J Shoulder Elbow Surg. 2000; 9:316-8

17. Borsa PA, Wilk KE, Jacobson JA, Scibeck JS, Dover GC, Reinold MM et al. Correlation of range of motion and glenohumeral translation in professional baseball pitchers. Am J Sports Med. 2005; 33:1392-9. 